\title{
A Contemplação do Criador na grandeza e beleza das Criaturas: Sb 13,5 no contexto da Laudato Si’ 12
}

\author{
The Contemplation of the Creator \\ in the Greatness and Beauty of the Creatures: \\ $\mathrm{Sb} 13.5$ in the Context of Laudato Si' 12
}

Fábio da Silveira Siqueira*

\section{Resumo}

$\mathrm{Na}$ Introdução da Encíclica Laudato Si', de modo particular, no n. 12, ao falar da fidelidade de São Francisco à Sagrada Escritura, o Papa evoca dois textos, um do Novo e outro do Primeiro Testamento, que apontam para o tema da contemplação do Criador na grandeza e beleza de suas criaturas. Do Primeiro Testamento, o Papa toma o texto de Sb 13,5, que se encontra na perícope de $\mathrm{Sb}$ 13,1-9. Embora tal perícope traduza a crítica do autor sagrado à vã idolatria das criaturas em lugar do Criador, o v.5 enuncia um princípio positivo, aquele da "analogia" ou "proporção" ( $\alpha$ v $\alpha \lambda$ ó $\gamma \omega \varsigma)$ pelo qual, através da contemplação das criaturas, pode-se chegar à contemplação do próprio Criador ( $\gamma \varepsilon v \varepsilon \sigma i o v \rho \gamma o ́ \varsigma)$. O objetivo deste artigo é apresentar uma breve exegese do texto de Sb 13,1-9, detendo-se, de modo particular, no v.5 e seu sentido no contexto da Encíclica Laudato Si'.

Palavras-chave: Livro da Sabedoria. Analogia. Criação. Monoteísmo.

\section{Abstract}

In the Introduction to the Encyclica Laudato $\mathrm{Si}^{\prime}$, in particular, n. 12, speaking of St. Francis's faithfulness to Holy Scripture, the Pope recalls two texts, one from the New and another from the First Testament, which point to

* Artigo submetido em 28/09/19 quando o autor ainda era doutorando na PUC-Rio. 
the theme of the contemplation of the Creator in the greatness and beauty of his creatures. From the First Testament, the Pope takes the text of Wis 13.5. While such a pericope translates the sacred author's critique of the vain idolatry of creatures rather than the Creator, v.5 enunciates a positive principle, that of "analogy" or "proportion" ( $\dot{\alpha} v \alpha \lambda$ ó $\omega \varsigma)$ whereby, through the contemplation of creatures, one can come to the contemplation of the Creator himself ( $\gamma \varepsilon v \varepsilon \sigma 10 u \rho \gamma o ́ \varsigma)$. The purpose of this article is to present a brief exegesis of the text of Wis 13:1-9, with particular attention to v.5 and its meaning in the context of the Encyclica Laudato Si'.

Keywords: Book of Wisdom. Analogy. Creation. Monotheism.

\section{Introdução}

$\mathrm{Na}$ introdução da encíclica Laudato Si', "Sobre o cuidado da casa comum", de 24 de maio de 2015, nos nn. 10-12, o Papa evoca São Francisco como um modelo "belo e motivador"1 para os que se debruçam sobre o tema da ecologia. Com o intuito de demonstrar que a atitude de São Francisco com relação ao cosmos estava em plena sintonia com a Sagrada Escritura, são evocados dois textos, ${ }^{2}$ um do Primeiro e outro do Novo Testamento. Do Primeiro Testamento é evocado o texto de $\mathrm{Sb} 13,5$, que se encontra na perícope de $\mathrm{Sb} 13,1-9$, no qual o autor sagrado fala da "vaidade" (no sentido de "vazio") ou da "estultícia" daqueles que, contemplando a criação, tendem a divinizar os elementos da natureza, não chegando a contemplar, por meio deles, o Criador. Um princípio teológico positivo é anunciado em $\mathrm{Sb}$ 13,5: o da analogia. Segundo esta categoria apresentada pelo texto sagrado, é possível ao homem chegar ao conhecimento do Criador por meio da contemplação da "grandeza" e "beleza" das criaturas. O objetivo deste artigo é apresentar uma breve exegese de Sb 13,1-9, com ênfase no v.5, refletindo, depois, sobre o sentido do texto no contexto da Laudato Si'. Para a exegese do texto, depois da segmentação, tradução e delimitação da perícope, serão seguidos alguns passos do método histórico-crítico, a fim de se estabelecer uma estrutura para o texto. O comentário exegético levará em conta seus aspectos semânticos considerando, de modo particular os termos raros que a perícope apresenta.

\footnotetext{
${ }^{1} \mathrm{LS} 10$.

${ }^{2}$ LS 12.
} 


\section{Segmentação e Tradução}

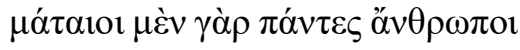

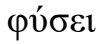

oĩ $\pi \alpha \rho \tilde{\eta} v \theta \varepsilon o \tilde{~} \alpha \dot{\gamma} v \omega \sigma i ́ \alpha$

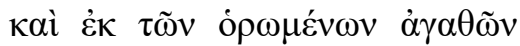

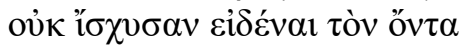

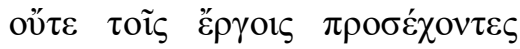

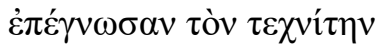

$\dot{\alpha} \lambda \lambda \lambda^{\prime} \grave{\eta} \pi \tilde{v} \rho$ iे $\pi v \varepsilon \tilde{v} \mu \alpha$ ì $\tau \alpha \chi i v o ̀ v$

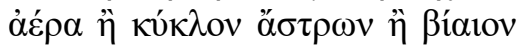

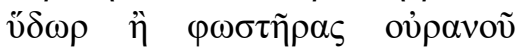

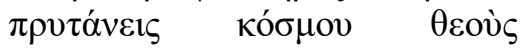
$\dot{\varepsilon} v o ́ \mu 1 \sigma \alpha \nu$

$\tilde{\omega} v \varepsilon i ̉ \mu \varepsilon ̀ v \tau \tilde{n} \kappa \alpha \lambda \lambda o v \tilde{n} \tau \varepsilon \rho \pi o ́ \mu \varepsilon v o เ$

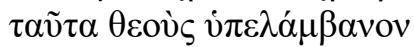

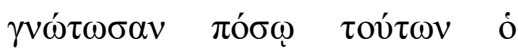

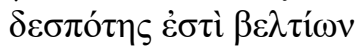

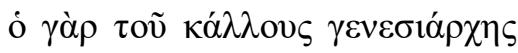

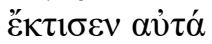

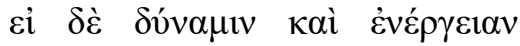
$\dot{\varepsilon} \kappa \pi \lambda \alpha \gamma \varepsilon \dot{v} v \varepsilon \varsigma$

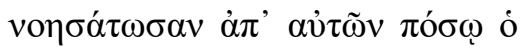

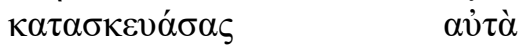

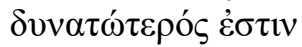

1a Vãos, de fato, por natureza, foram todos os homens

1b nos quais esteve presente a ignorância de Deus

e que, partindo dos bens visíveis,

1c não foram capazes de reconhecer Aquele que é,

1d nem, considerando as obras, reconheceram o Artífice.

Mas, ou o fogo, ou o vento, ou o ar sutil, ou o círculo dos astros, ou a água impetuosa, ou as estrelas do céu, eles os reconheceram deuses, regentes do mundo!

3a Se, pois, encantados com sua beleza, os tomaram por deuses,

saibam quão superior (melhor) ${ }^{3}$ é o Senhor deles;

3c de fato, o Autor $^{4}$ da beleza os criou.

Se os deixou estupefatos sua força e atividade,

entendam quão mais poderoso é aquele que os formou.

${ }^{3} \mathrm{O}$ termo $\beta \varepsilon \lambda \tau i ́ \omega v$ é comparativo do adjetivo $\alpha \gamma \alpha \theta$ ó $\varsigma$ podendo significar, também, "melhor, preferível" etc. (BAILLY, A., $\beta \varepsilon \lambda \tau i ́ \omega v$, p. 356).

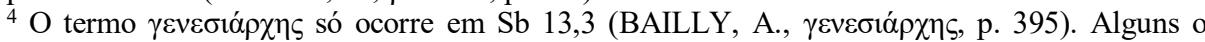
traduzem como "autor", outros como "fonte" (NICCACCI, A., Il Libro della Sapienza, p. 134). 


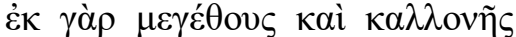
$\kappa \tau \imath \sigma \mu \alpha ́ \tau \omega v \quad \dot{\alpha} v \alpha \lambda o ́ \gamma \omega \varsigma \quad \dot{0}$

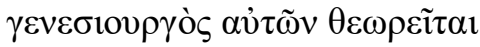

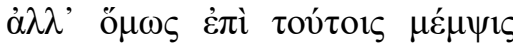
$\dot{\varepsilon} \sigma \tau i \mathrm{v}$ ỏ $\lambda \hat{\gamma} \gamma$

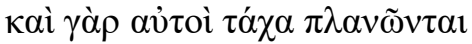

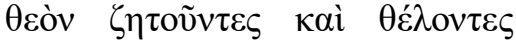

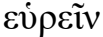

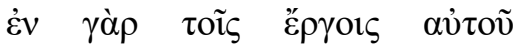

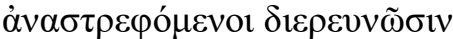

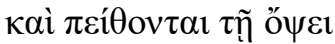

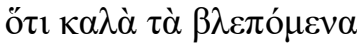

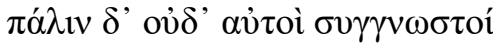

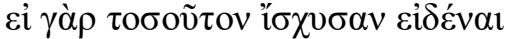

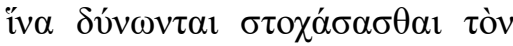
$\alpha i \tilde{\omega} v \alpha$

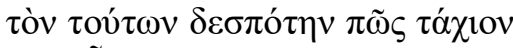

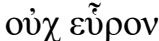

De fato, na grandeza e beleza das criaturas pode ser contemplado, por analogia, o seu Criador.

Mas, todavia, a reprovação para estes é menor,

6b pois, talvez se tenham extraviado

buscando a Deus e desejando encontrá-lo.

Com efeito, vivendo entre as suas obras, eles o procuram,

$7 \mathrm{~b}$

mas se deixam levar pela aparência,

$7 \mathrm{c}$

pois são belas as coisas que são vistas!

Mesmo assim, eles não são desculpáveis!

Se, pois, foram capazes de

$9^{\text {a }}$ conhecer coisas assim grandiosas,

$9 \mathrm{~b}$ de modo que puderam investigar o mundo,

9c como não encontraram, mais facilmente, o seu Senhor?

\section{A organização do texto: delimitação, crítica da forma e estrutura}

Considera-se que a perícope $\mathrm{Sb}$ 13,1-9 encontra-se na terceira parte do livro da Sabedoria (Sb 10,1-19,21), que apresenta uma reflexão sobre a história. Nos caps. 13-15 é apresentado o tema da idolatria, começando em 13,1 com a afirmação do "vazio" no qual caminham os homens que não chegam a conhecer a Deus, mas se perdem na aparência das coisas (Sb 13,7). Uma das 
razões para se fazer o corte da perícope no v. 9 é a presença de um outro adjetivo, $\tau \alpha \lambda \alpha i ́ \pi \omega \rho \varsigma_{\varsigma}$ (miseráveis), que parece abrir uma outra unidade textual (Sb 13,10-19), onde embora se continue a tratar do tema da idolatria, a crítica não está mais relacionada ao culto às forças da natureza, mas sim a algo considerado pior: o culto de imagens sem vida, feitas pelas mãos de um artesão

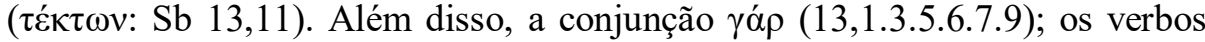
que indicam a capacidade de "conhecer" ou "reconhecer" alguém ou alguma coisa, como oĩ $\delta \alpha(13,1.9)$, vo

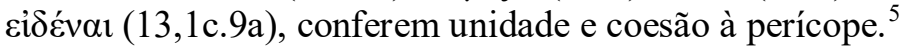

Aberto pelo adjetivo $\mu \alpha$ á $\alpha 10 \zeta$, nos vv.1-2 o texto apresenta verbos de

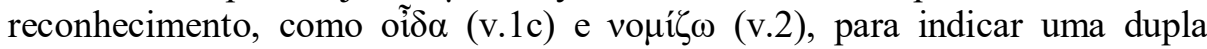
atitude: de um lado, o "não" reconhecimento de Deus (v.1c) e, de outro, a consideração de que as forças da natureza deviam ser divinizadas (v.2). Os "bens visíveis" indicados no v.1c, são descritos no v.2: fogo, vento, ar sutil, círculo dos astros, água impetuosa e as estrelas do céu. Uma outra contraposição é criada nos vv.1-2 entre "Aquele que é" (v.1c), o "Artífice" do universo (v.1d) e os "deuses", reputados como "regentes do mundo" (v.2).

Nos vv.3-4, o termo $\pi$ ó $\sigma o \varsigma$ é utilizado em conjunto com os adjetivos $\grave{\alpha} \gamma \alpha \theta$ ó e $\delta v v \alpha \tau o ́ \varsigma$ em grau comparativo, para se criar uma "inclusão", formando

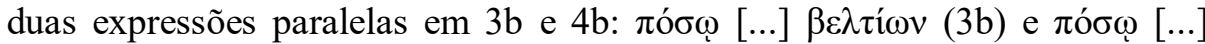
$\delta v v \alpha \tau \omega ́ \tau \varepsilon \rho o ́ \varsigma(4 b)$. Nestes versículos se confronta, de um lado, a "beleza"

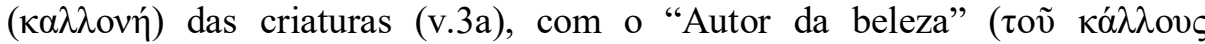

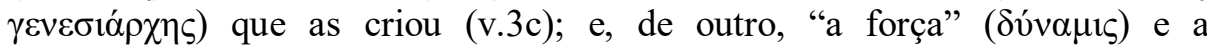

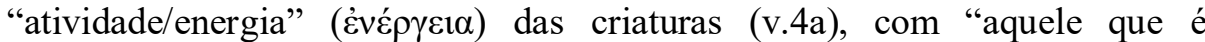

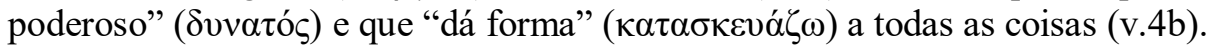
Os segmentos $3 \mathrm{~b}$ e $4 \mathrm{~b}$ ganham caráter exortativo, pelo uso do imperativo aoristo dos verbos $\gamma ı$ reconhecer a Deus como "Autor da beleza". O v.5, por sua vez, ocupa uma posição central na perícope. Ele sintetiza o que foi dito antes por meio de uma afirmação em tom positivo. Ao evocar a "grandeza" e a "beleza" das criaturas, o autor sagrado retoma o que fora exposto nos vv.3a (3a/5a: $\kappa \alpha \lambda \lambda o v \eta ́)$ e $4 \mathrm{a}$ (4a:

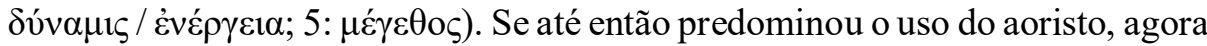
o autor sagrado apresenta uma sentença de validade geral utilizando o indicativo presente passivo do verbo $\theta \varepsilon \omega \rho \varepsilon ́ \omega$. O versículo apresenta dois hápax

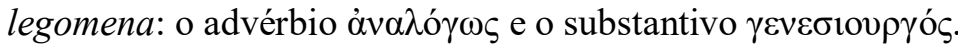

Os vv.6-7 são marcados por verbos que indicam a atitude de investigar,

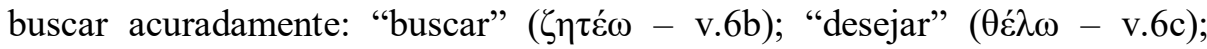

${ }^{5}$ LINDEZ, J. V., Sabedoria, p. 286. 


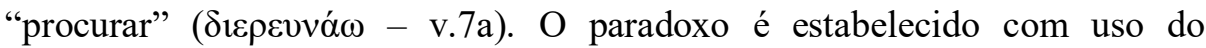
indicativo presente passivo dos verbos "extraviar-se" ( $\pi \lambda \alpha v \alpha$ a: v.6b) e "deixarse levar/persuadir/convencer" ( $\pi \varepsilon i \theta \omega:$ v.7b). Os vv.8-9, por sua vez, parecem servir de conclusão para a perícope, pois retomam termos e expressões dos

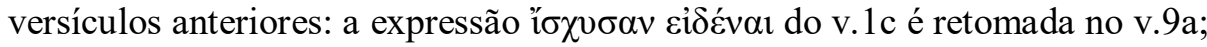

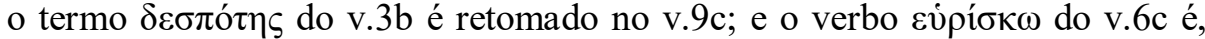
também, retomado no v.9c. Além disso, o adjetivo $\sigma 0 \gamma \gamma v \omega \sigma \tau o$ do v.8, utilizado

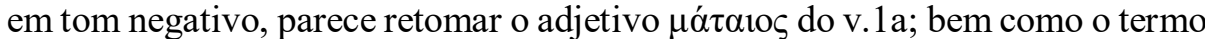

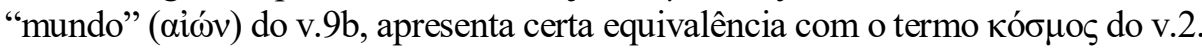

A partir desta breve análise, pode-se constatar que a perícope é desenvolvida por meio de antíteses, ${ }^{6}$ imagens contrapostas que se explicam mutuamente, sendo possível, então, estruturá-la da seguinte forma:

\begin{tabular}{|c|}
\hline .1-2: Intr \\
\hline 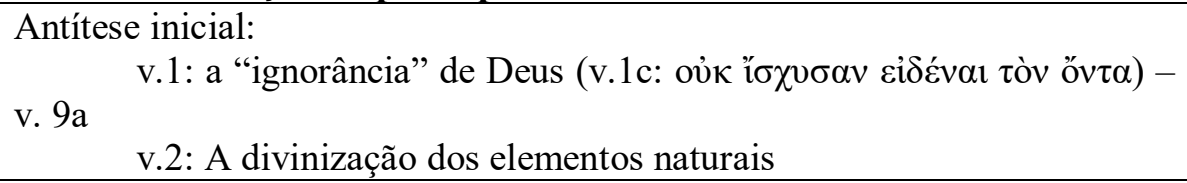 \\
\hline vv.3-7: Corpo do texto \\
\hline vv.3-4: Primeira Parte - Duas con \\
\hline 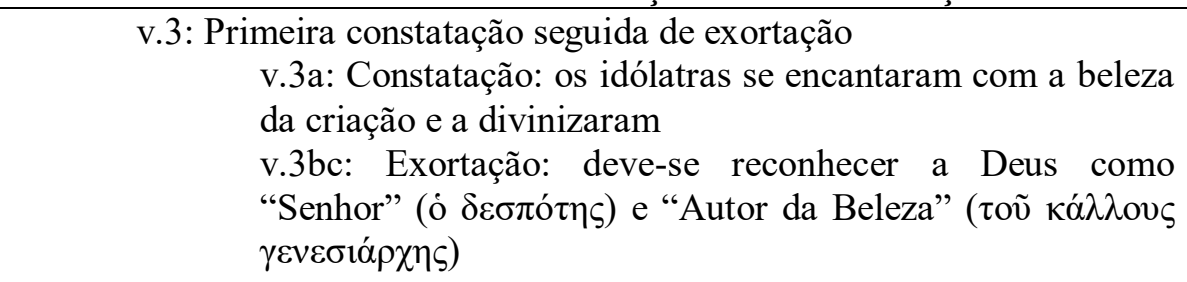 \\
\hline $\begin{array}{l}\text { v.4: Segunda constatação seguida de exortação } \\
\text { v.4a: Constatação: os idólatras ficaram estupefatos com a } \\
\text { força e a atividade das forças da natureza e as divinizaram } \\
\text { v.4b: Exortação: deve-se reconhecer a Deus como aquele } \\
\text { que é "mais poderoso" e que "formou" todas as coisas }\end{array}$ \\
\hline v.5: Parte central: o princípio da "analogia" e o "Deus Genesiurgo" \\
\hline
\end{tabular}

${ }^{6}$ LINDEZ, J. V., Sabedoria, p. 286. 


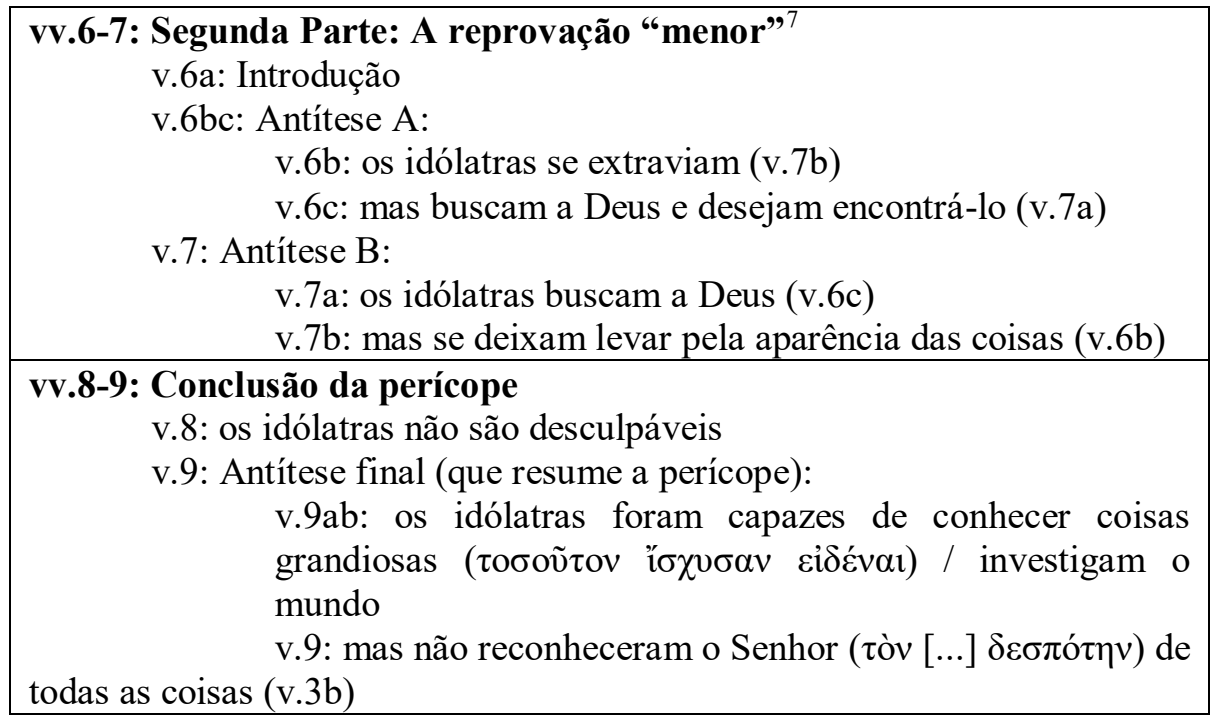

\section{Comentário exegético}

São consideradas no comentário as diversas seções do texto, já estabelecidas previamente quando da sua estruturação, com exceção do v.5, que será comentado à parte, no item 4 , onde será melhor analisado seu uso no contexto do n. 12 da Laudato Si'.

\subsection{Introdução: a ignorância de Deus (vv.1-2)}

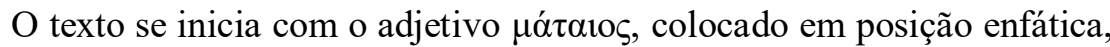

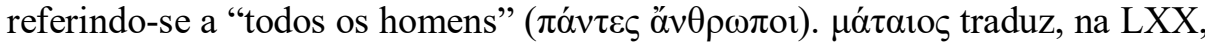

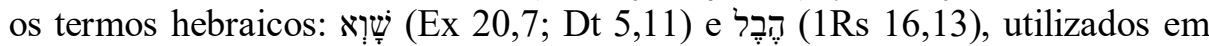
alguns contextos para referir-se à idolatria. O uso do termo שְׁ em Ex 20,7 e

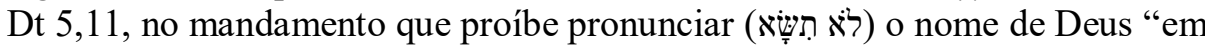
vão", faz com que se pense que tratar-se-ia de algum tipo de encantamento ou magia com o nome de YHWH, com o objetivo de forçar sua presença e atuação.

\footnotetext{
${ }^{7}$ Aqui o texto aponta para a perícope seguinte, $\mathrm{Sb}$ 13,10-19, onde a fabricação de ídolos é considerada uma idolatria pior do que a daqueles que divinizaram as forças da natureza. Os paradoxos estabelecidos em Sb 13,17-19 apontam nesse sentido.

8 O termo שְׁ pode significar "inútil, fútil, falso, vazio ou vão" (KOEHLER, L.;

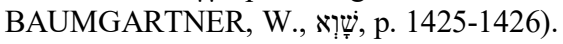


Seria uma forma "idolátrica" de se comportar diante de Deus, como se ele fosse semelhante aos deuses dos povos circunvizinhos. ${ }^{9}$

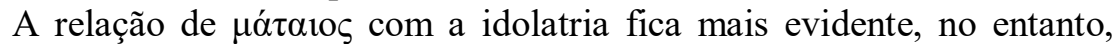
quando o termo traduz, na LXX, o termo הבל הבר הe que no qal significa "tornar-se inútil ou ocupar-se de coisas inúteis" e, no hifil, tem o sentido de tornar alguma coisa "inútil" ou "vazia", 10 o termo é traduzido normalmente como "sopro, vazio ou vaidade". ${ }^{11}$ Em Dt 32,21 e 1Rs 16,13.26

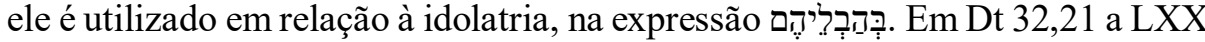

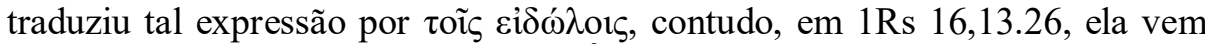

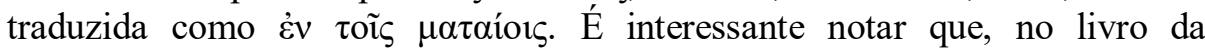

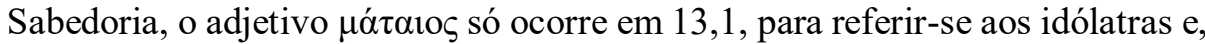

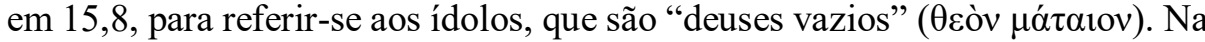

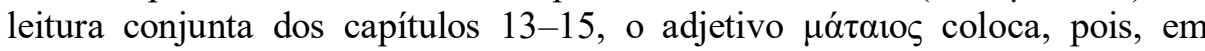
relação de igualdade, os idólatras e os ídolos: são "vãos" os que adoram os "ídolos vãos". Com isso, o autor do livro da Sabedoria alinha-se à mentalidade bíblica no seu conjunto, que afirma que os adoradores dos ídolos acabam por tornar-se semelhantes àqueles a quem adoram $\left(\mathrm{Sl} \mathrm{115,8)}{ }^{12}\right.$

A expressão $\pi \alpha ́ v \tau \varepsilon \zeta ~ \alpha ̋ v \theta \rho \omega \pi$ ol $\varphi v ́ \sigma \varepsilon 1$ do v.1a parece referir-se não à humanidade no seu conjunto, mas aos que se comportaram de acordo com aquilo o que o texto critica, ou seja, aqueles que "ignoraram a Deus" e que não foram capazes de reconhecer "Aquele que é" a partir da observação das coisas visíveis. ${ }^{13}$ A expressão "Aquele que é" ( $\tau$ òv öv $\tau \alpha$ ) retoma as tradições do Exxodo, particularmente Ex 3,14, onde a LXX traduz como ó ஸ̂v a expressão

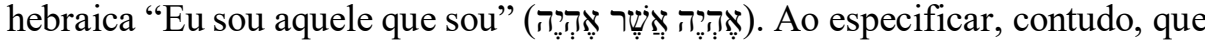
"Aquele que é" (v.1c) é, também, o "Artífice" da criação (v.1d), o autor sagrado elimina qualquer possibilidade de se conceber, como concebia a filosofia platônica, um ser intermediário, um demiurgo, que seria o responsável por plasmar a criação. ${ }^{14}$

A contraposição entre os vv.1 e 2 é sublinhada pelo uso da conjunção adversativa $\dot{\alpha} \lambda \lambda \dot{\alpha}$ no início do v.2. Aqui o autor sagrado esclarece melhor qual o sentido da expressão $\theta \varepsilon$ oṽ $\alpha \gamma v \omega \sigma i ́ \alpha$ do v. 1 b: além de não reconhecer Deus por meio das suas obras, os homens reputaram como deuses as realidades terrenas que contemplaram. São enumerados seis elementos: o fogo, o vento, o ar sutil,

\footnotetext{
${ }^{9}$ SAWYER, J. F. A., שִָׁׁ, cc. 1108-1109.

${ }^{10}$ ALBERTZ, R., הבֶ, c. 659.

11 ALONSO SCHÖKEL, L., הֶֶ, p. 166.

${ }^{12}$ Para a numeração dos Salmos segue-se a Bíblia Hebraica.

${ }^{13}$ LINDEZ, J. V., Sabedoria, p. 287.

${ }^{14}$ LINDEZ, J. V., Sabedoria, p. 288.
} 
o círculo dos astros, a água impetuosa e as estrelas do céu. A referência ao círculo dos astros e às estrelas do céu é compreensível no conjunto do Antigo Testamento, onde em outros textos aparece explícita a condenação dos cultos astrais (Dt 4,19; 2Rs 23,4). Todavia, a menção dos elementos primordiais fogo, vento, ar, água - faz com que os estudiosos do livro da Sabedoria pensem que pode tratar-se de uma referência às correntes filosóficas em voga no momento da redação do livro, de modo particular, o estoicismo. ${ }^{15}$

\subsection{Corpo do texto (vv.3-7)}

O corpo do texto pode ser dividido em três partes. A parte central, o v.5, será comentada à parte. Aqui serão apresentadas a primeira e a segunda parte do corpo do texto que trazem, respectivamente, a exortação a se reconhecer o Criador por meio das suas obras (vv.3-4) e a reprovação "menor" que recebem esses idólatras.

a) Primeira parte (vv.3-4): exortação a se reconhecer o Criador

Nos vv.3-4 a antítese é marcada pelo uso da partícula $\varepsilon i ̉$ (vv.3a.4a),

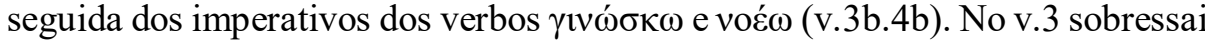

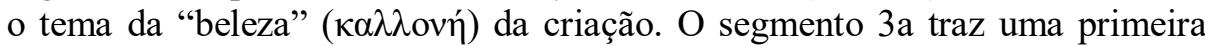
constatação: encantados com a beleza dos elementos do mundo material, os homens os tomaram por deuses. Estes são exortados, então, a saber que o "Senhor" (ó $\delta \varepsilon \sigma \pi$ ó $\eta \varsigma)$ de todas essas coisas é o próprio "Autor da beleza" ( $\tau$ oṽ

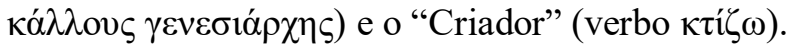

$\mathrm{O}$ autor do livro da Sabedoria utiliza, no v.3bc, dois epítetos para se

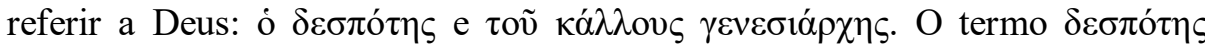
aplicado a YHWH não é estranho à LXX, onde é utilizado, algumas vezes, para traduzir o tetragrama sagrado (Is 1,$24 ; 3,1 ; 10,33 ;$ Jr 1,6). No livro da Sabedoria, à exceção de 18,11 , o termo refere-se sempre a YHWH. ${ }^{16} \mathrm{~A}$ expressão $\tau$ oṽ

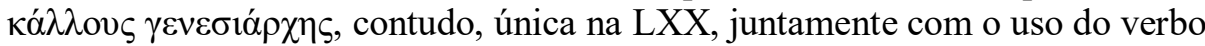
$\kappa \tau i \zeta \omega$ em 3c, parecem apontar para as tradições do Gênesis. No princípio de tudo, na origem da beleza, está aquele que é sua "fonte" ou seu "autor" (Gn

${ }^{15}$ GILBERT, M., La critique des Dieux dans le livre de la Sagesse, p. 14: "Sg 13,2 semble viser le stoïcisme. On sait que les stoïciens, tout autant que le jeune Aristote, ont professe une sorte de monothéisme cosmique, de panentheísme où la transcendance absolute et immaterielle de Dieu ne se trouvait pas affirmé. Or ces idées étaient répandues dans le monde méditerranéen au temps où écrit l'auteur."

${ }^{16}$ Conferir a ocorrência do termo em Sb 6,7; 8,3; 11,26; 13,3.9. 
1,1). ${ }^{17}$ Daqueles que se "encantaram/fascinaram" (v.3a) com a beleza da criação, vem exigido, em contraposição, através do imperativo do verbo $\gamma \iota \omega ́ \sigma \kappa \omega,{ }^{18}$ o reconhecimento daquele que é "Senhor", "Autor da beleza" e "Criador" de todas as coisas.

O autor sagrado, em consonância com a mentalidade bíblica, reconhece a bondade/beleza da criação, afinal, depois de terminar sua obra, Deus viu que

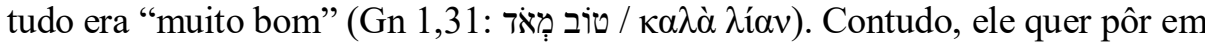
evidência que, acima de tudo o que é "bom e belo", existe o que é "melhor", o próprio Deus que criou todas as coisas. Isso fica textualmente expresso pelo uso da expressão $\pi$ ó $\sigma \omega[. ..] \beta \varepsilon \lambda \tau i ́ \omega v(3 b)$ e será confirmado mais adiante, no v.7c.

No v.4 encontra-se a segunda antítese desta parte da perícope que, nos moldes do v.3, também traz uma constatação (4a) seguida de uma exortação

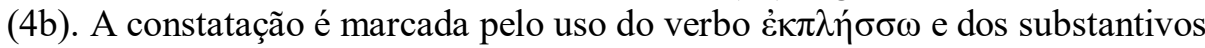

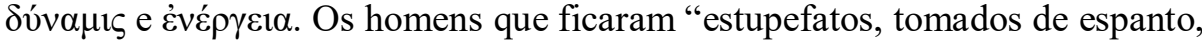
tomados de temor" $(\dot{\varepsilon} \kappa \kappa \lambda \eta \dot{\sigma} \sigma \sigma \omega){ }^{19}$ diante da "força" e da "atividade" dos elementos da natureza descritos no v.2 são, agora, exortados (4b) a reconhecer que aquele que formou todas as coisas é mais poderoso. A contraposição é marcada, a exemplo do que ocorre no v.3, tanto pelo uso da expressão $\pi$ ó $\sigma \omega$

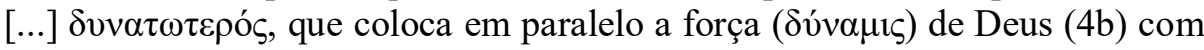
a força $(\delta v ́ v \alpha \mu \iota \varsigma)$ dos elementos criados (4a), quanto pelo uso do verbo voźc no

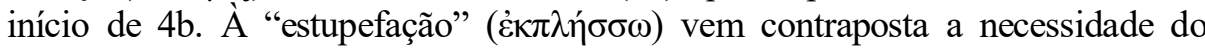
"entendimento" (voź $\omega$ ) de que foi o próprio Deus quem "formou" todas as coisas.

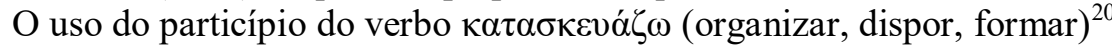
parece remeter mais uma vez para as tradições do Gênesis, de modo particular

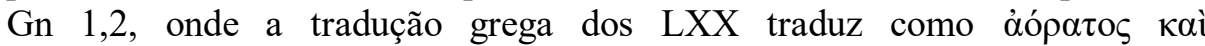

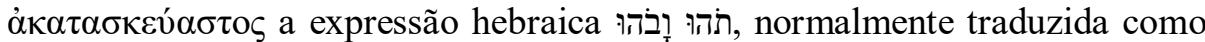

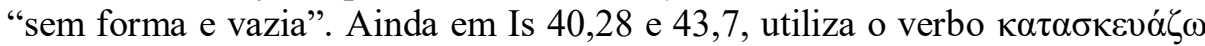
para traduzir o particípio da raiz ברא, que também se encontra nas tradições do Gênesis $(\mathrm{Gn} 1,1)$. Com isso o autor reforça o motivo pelo qual se deve procurar o "conhecimento" (voź( ) de Deus: foi ele quem, no início, deu forma/criou tudo aquilo o que desperta o fascínio dos homens que contemplam a criação.

\footnotetext{
${ }^{17}$ LINDEZ, J. V., Sabedoria, p. 292.

${ }^{18} \mathrm{O}$ verbo $\gamma ı$ iv́ $\sigma \kappa \omega$ conecta-se com as tradições proféticas de Israel e, de modo particular, com a necessidade de se buscar a עַּ̣ $/ \gamma \nu \tilde{\sigma} \sigma 1 \zeta$, tão necessária para se viver uma real comunhão com Deus (Os 4,6; Ml 2,7).

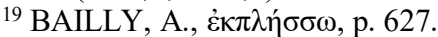

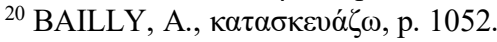


b) Segunda parte (vv.6-7): A reprovação menor

A segunda parte do corpo do texto introduz o tema da "reprovação" ( $\mu \varepsilon ́ \mu \psi 1 \varsigma)$ menor. Esta expressão parece antecipar, de modo proléptico, o que virá descrito em Sb 13,10-19: os que fabricam os ídolos merecem uma reprovação mais severa, pois adoram a obra feita pelas suas próprias mãos. Nesse sentido, são mais abjetos do que aqueles que, fascinados pela força da criação, não conseguiram elevar o seu pensamento ao nível do conhecimento de Deus, permanecendo na imanência. Os vv.6-7 são marcados, também, por duas antíteses (v.6bc.7ab), que são apresentadas valendo-se do recurso estilístico do paralelismo:

A: Os idólatras se extraviam (6b)

B: Mas buscam e desejam encontrar a Deus (6c)

B: Os idólatras buscam a Deus (7a)

A: Mas se perdem na aparência das coisas (7b)

O v.6b traz os verbos $\pi \lambda \alpha v \alpha ́ \omega$ (extraviar-se) e $\zeta \eta \tau \varepsilon ́ \omega$ (buscar). O verbo $\pi \lambda \alpha v \alpha ́ \omega$ normalmente é utilizado na LXX em sentido religioso, para indicar não o simples afastamento físico, mas o "desviar-se" da vontade de YHWH. Algumas vezes, traduz as raízes hebraicas תעה e vem associado com a ideia da idolatria (Dt 4,19; Ez 44,10). ${ }^{21}$ A culpabilidade dos que se "extraviam" é amenizada, conforme assevera o v.6a, porque eles "buscam" e desejam "encontrar" a Deus. O tema da busca de Deus é apresentado em 6b por meio do particípio dos verbos $\zeta \eta \tau \dot{\varepsilon} \omega$ e $\theta \dot{\varepsilon} \lambda \omega$. O verbo $\zeta \eta \tau \dot{\varepsilon} \omega$ traduz, algumas vezes, na LXX, a raiz בקש (2Cr 7,14; 11,16; Jr 27,4), que ocorre na BH no Piel e no Pual, sendo muito mais frequente a forma Piel. ${ }^{22}$ Seu sentido literal é "procurar" e indica a ação do sujeito que procura por uma pessoa ou coisa, podendo ser utilizada em sentido próprio (Gn 37,15-16) ou metafórico (Sl 4,3). Em sentido teológico, tal raiz pode ter YHWH como sujeito ou como objeto. ${ }^{23}$ Tendo

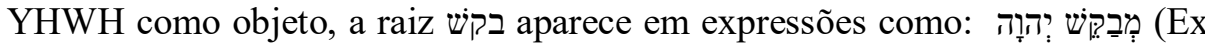

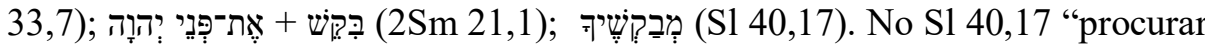

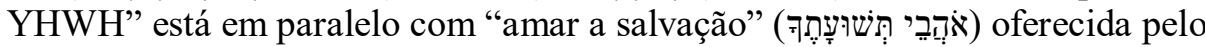
próprio YHWH. Nesta passagem e em outras (Sl 69,7; 70,5; 105,3-4; 1Cr

${ }^{21}$ BRAUN, H., $\pi \lambda \alpha v \alpha ́ \omega$, p. 234.

${ }^{22}$ Das cerca de 225 ocorrências do verbo na BH, apenas 3 são no Pual (Jr 50,20; Ez 26,21; Est 2,23). Todas as demais ocorrências são no Piel (LISOWSKY, G., Konkordanz zum Hebräischen Alten Testament, p. 277-279).

${ }^{23}$ SIEGFRIED, W., 
16,10-11) o termo tem sempre uma acepção positiva. Indica uma atitude piedosa em relação a YHWH. ${ }^{24}$ Aqui fica explícito, então, o primeiro motivo pelo qual a culpabilidade desses idólatras é, de certo modo, amenizada em relação àqueles que serão apresentados em $\mathrm{Sb}$ 13,10-19: eles possuem o desejo de encontrar a Deus, no entanto, não chegam a alcançá-lo.

O v.7 explicita melhor o conteúdo do v.6: os idólatras se perdem porque se deixam levar pela "aparência" (ő $\psi 1 \zeta$ ) das coisas. Ao contrário do que ocorre no v.6bc, no v.7a o autor sagrado começa por uma afirmação positiva: vivendo entre as obras de Deus, os homens o procuram ( $\delta \varepsilon \varepsilon \rho \varepsilon v v \alpha ́ \omega)$. O verbo $\delta 1 \varepsilon \rho \varepsilon v v \alpha ́ \omega$, que pode significar "procurar acuradamente, explorar, pesquisar cuidadosamente" 25 só é utilizado no livro da Sabedoria, nesta perícope e em $\mathrm{Sb}$ 6,3, sendo que em Sb 6,3 o sujeito é Deus, que "perscruta" o desejo dos homens. $\mathrm{O}$ autor sagrado ameniza mais uma vez a culpabilidade dos idólatras justificando que eles buscam a Deus, mas se deixam levar pela "aparência" das coisas, ou seja, não conseguem dar o necessário salto para perceber o Criador que se esconde e revela por meio das suas criaturas. O versículo termina com o reconhecimento da beleza/bondade da Criação expressa através do adjetivo

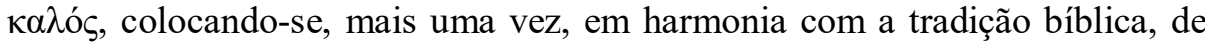
modo particular com as tradições do Gênesis, onde o próprio YHWH é apresentado como "aquele que viu" que tudo era "muito bom" (Gn 1,31). O autor sagrado, ao mesmo tempo em que atenua a culpabilidade destes "homens vãos" (Sb 13,1), alerta sobre o perigo que comporta uma tarefa em si muito positiva, que é a investigação da natureza: o perigo de não se transcender, passando da contemplação das criaturas para o reconhecimento do Criador.

\subsection{A conclusão da perícope (vv.8-9): os idólatras não são desculpáveis}

Os vv.8-9, que funcionam como conclusão para a perícope no seu conjunto, retomam e sintetizam os elementos anteriormente desenvolvidos. $\mathrm{O}$ advérbio $\pi \alpha ́ \lambda ı v$, utilizado algumas vezes para indicar uma contraposição de ideias, conecta o v.8 com os vv.6-7, mostrando que, embora a culpabilidade dos

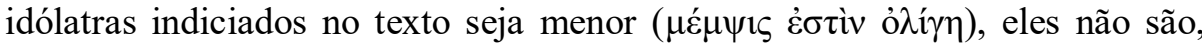
todavia, "desculpáveis" ( $\sigma 0 \gamma \gamma \nu \omega \sigma \tau o i ́) . ~ \sigma v \gamma \gamma \nu \omega \sigma \tau o i ́$, que significa "perdoável, excusável", ${ }^{26}$ é mais um termo raro na LXX, que pertence somente ao vocabulário do livro da Sabedoria, aparecendo nessa perícope e em Sb 6,6. Ele

\footnotetext{
${ }^{24}$ SIEGFRIED, W., 239.

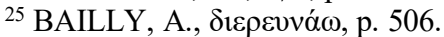

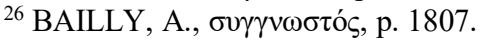




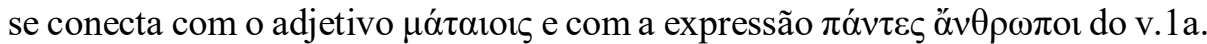
O motivo pelo qual eles não são excusáveis vem explicitado no v.9, através da antítese final, que encerra a perícope.

A primeira parte da antítese está no v. 9ab, onde a expressão í $\sigma \chi v \sigma \alpha v$

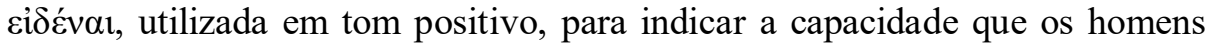
tiveram de conhecer "coisas grandiosas", é retomada do v.1c, criando uma inclusão: os que, partindo dos bens visíveis, não foram capazes de reconhecer Aquele que é (v.1c), foram capazes, no entanto, de conhecer "coisas grandiosas" (v.9a). O autor reconhece o grande valor que possui o homem que

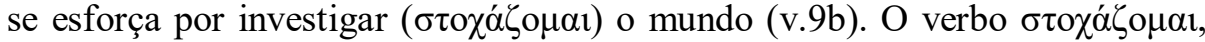
que significa "investigar, conjecturar", pertence ao mesmo campo semântico

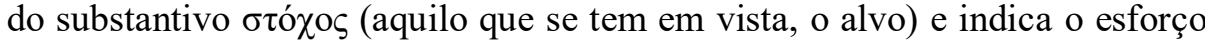
próprio de quem se empenha em conhecer de modo acurado alguma coisa. ${ }^{27}$ Grande esforço os homens dispenderam em conhecer a obra da criação e os elementos que compõem o mundo (v.2), contudo, sua culpa se torna manifesta porque, mesmo com tanto esforço, não chegaram a cumprir plenamente sua jornada, pois não reconheceram, partindo das realidades visíveis, o Criador de todas as coisas.

É no v.9c que o autor manifesta agora sua estupefação através do

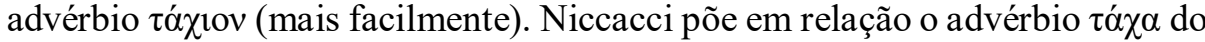
v.6b e o advérbio táxiov do v.9c, estabelecendo um paralelo entre os dois

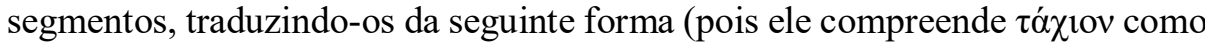
um comparativo): ${ }^{28}$

v.6b: pois, "facilmente" ( $\tau$ ó $\chi \alpha)$ se enganam v.9c: como não encontraram, "mais facilmente" ( $\tau$ áxıov), o seu Senhor?

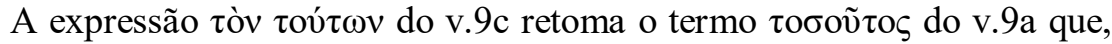
por sua vez, faz referência ao cosmo, designado pelos termos кó $\sigma \mu \mathrm{s}$ (v.2) e

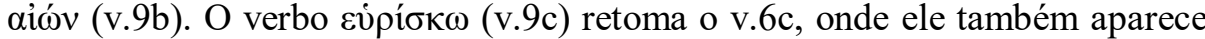
na descrição no motivo pelo qual estes idólatras recebem uma punição mais branda. A conclusão é clara: embora mais branda, há uma reprovação dirigida contra os que adoram as forças da natureza, reputando-as como se fossem deuses. A reprovação se baseia no fato de que os homens "foram capazes", "tiveram inteligência", "procuraram acuradamente" conhecer tudo o que há na

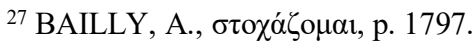

${ }^{28}$ NICCACCI, A., Il Libro della Sapienza, p. 136. 
terra e sobre o céu, mas no entanto não chegaram a conhecer o Artífice (v.1d), o Autor da beleza (v.3c), o Senhor de todas as coisas (vv.3b.9c).

\section{O uso de Sb 13,5 na Laudato Si’ 12}

A parte central da perícope é o v.5, onde o autor sagrado expõe o princípio da "Analogia" 29 e apresenta Deus como "Genesiurgo". O autor começa retomando os versículos anteriores: o termo $\mu$ ź $\gamma \varepsilon$ os (grandeza) retoma

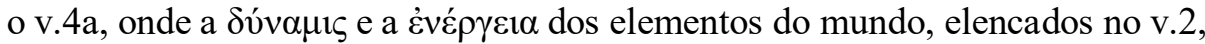

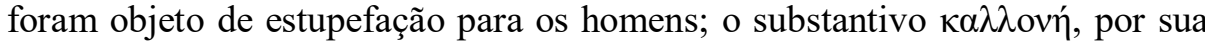
vez, evoca o v.3a, onde ele é utilizado no segmento onde se constata que a beleza das coisas criadas foi um dos fatores que levou à sua divinização da parte dos homens reputados como "vãos" (v.1a).

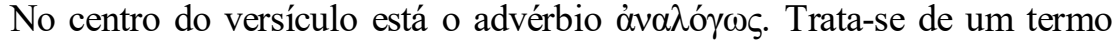
conhecido entre os filósofos de então, cujo sentido primitivo é o da proporção matemática. Ele é utilizado para indicar que, entre dois objetos que gozam de alguma semelhança, pode-se estabelecer certa relação. ${ }^{30}$ No contexto do v.5, seu uso indica que existe tal relação entre a obra da criação e o Criador, o que permite que, nesta, se possa "contemplar" $(\theta \varepsilon \omega \rho \varepsilon ́ \omega)$ a Deus. Contudo, para evitar justamente o mal que quer combater, o de se confundir Deus e o criado, o autor sagrado se vale dos comparativos já comentados acima nos vv.3b e $4 \mathrm{~b}$ para mostrar que Deus está acima da obra da criação, como seu "autor". Se a criação é "bela", sua beleza encontra sua "gênese" (v.3c) em Deus; se a criação se apresenta poderosa, cheia de energia, "mais poderoso" (v.4b) é aquele que a formou. Segundo Líndez, "Sb 13,5 é o primeiro texto conhecido em toda a literatura grega onde se aplica o esquema de proporção (analogia) à relação criatura-Deus". ${ }^{31}$ Segundo o mesmo autor, os vv.3-5 não apresentam uma "doutrina de escola", mas indicam a reta orientação do pensamento em relação a Deus. ${ }^{32}$

O v.5 traz mais um título que o autor sagrado atribui a Deus: ó

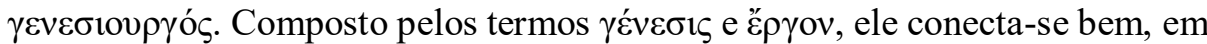
primeiro lugar, com a perícope em si. Assim, aquele que já foi apresentado

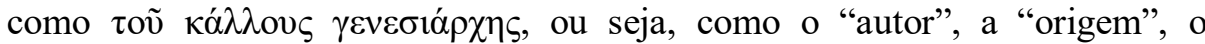
"genesiarca" da beleza, é agora apresentado como o "autor", a "origem", aquele onde se encontra a "gênesis" de tudo o que pode ser contemplado na criação:

\footnotetext{
${ }^{29}$ Tal princípio, desenvolvido sobretudo no período Escolástico, vai tornar-se, na Teologia, a via média entre o apofatismo e a univocidade (LAFONT, G., Analogia, p. 53-54).

${ }^{30}$ LINDEZ, J. V., Sabedoria, p. 294-295.

${ }^{31}$ LINDEZ, J. V., Sabedoria, p. 294.

${ }^{32}$ LINDEZ, J. V., Sabedoria, p. 294.
} 


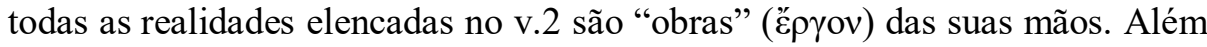
de se conectar com a perícope em si, o v.5, por meio do termo $\gamma \varepsilon v \varepsilon \sigma i o u \rho \gamma o ́ s$, conecta $\mathrm{Sb}$ 13,1-9 mais uma vez com as tradições do Gênesis. De modo

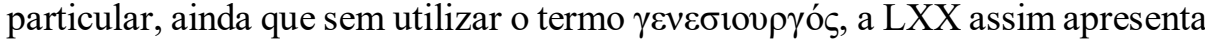
Deus ao utilizar o termo ěprov em Gn 2,2.3 para se referir ao conjunto das

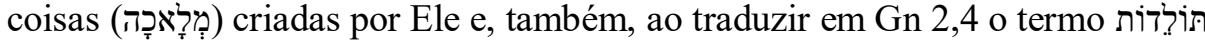
pela expressão $\eta \dot{\beta} \beta \dot{\beta} \lambda \lambda_{0 \varsigma} \gamma \varepsilon v \varepsilon \dot{\sigma \varepsilon} \omega \varsigma$.

O não reconhecimento do Criador na beleza e grandeza das suas criaturas implica num duplo perigo: ${ }^{33}$ o primeiro, denunciado em $\mathrm{Sb}$ 13,1-9, é a idolatria. No contexto, pois, de $\mathrm{Sb} 13,1-9$, o v.5 tem como finalidade demonstrar que a investigação ( $\mathrm{Sb}$ 13,9b) da natureza deve ser um caminho para a transcendência, para o conhecimento de Deus, o Deus da beleza, que se manifesta nas suas obras belas ( $\mathrm{Sb} 13,7 \mathrm{c})$; o segundo perigo que reside no não reconhecimento de Deus como a fonte da beleza que é visível no universo é a "dessacralização do mundo", um modo materialista de conceber a natureza que pode levar a um extrativismo abusivo, onde a exploração da criação e o nãocuidado com a casa comum se justificam em nome do lucro de alguns.

Esse segundo aspecto parece ser o primeiro visado quando se cita $\mathrm{Sb} 13,5$ no contexto da LS 12. São Francisco é apresentado como modelo do homem que reconhece a Deus por meio de suas obras. ${ }^{34}$ Como bem recorda LS 11, ele

${ }^{33}$ Esse "duplo perigo" foi apresentado pelo Papa Emérito Bento XVI na Encíclica Caritas In Veritate n. 48: "Na natureza, o crente reconhece o resultado maravilhoso da intervenção criadora de Deus, de que o homem se pode responsavelmente servir para satisfazer as suas legítimas exigências - materiais e imateriais - no respeito dos equilíbrios intrínsecos da própria criação. Se falta esta perspectiva, o homem acaba por considerar a natureza um tabu intocável ou, ao contrário, por abusar dela. Nem uma nem outra destas atitudes corresponde à visão cristã da natureza, fruto da criação de Deus".

${ }^{34}$ Laudato $S i$ ' coloca-se na esteira da preocupação com a ecologia que permeou o Magistério dos últimos Pontífices. Basta recordar, por exemplo, a Carta Apostólica Octogesima Adveniens, no n. 21: "À medida que o horizonte do homem assim se modifica, a partir das imagens que se selecionam para ele, uma outra transformação começa a fazer-se sentir, consequência tão dramática quanto inesperada da atividade humana. De um momento para outro, o homem toma consciência dela: por motivo da exploração inconsiderada da natureza, começa a correr o risco de destruí-la e de vir a ser, também ele, vítima dessa degradação. Não só já o ambiente material se torna uma ameaça permanente, poluições e lixo, novas doenças, poder destruidor absoluto; é mesmo o quadro humano que o homem não consegue dominar, criando assim, para o dia de amanhã, um ambiente global, que poderá tornar-se-lhe insuportável. Problema social de envergadura, este, que diz respeito à inteira família humana". Poder-se-ia evocar, ainda, a mensagem para o Dia Mundial da Paz do Papa São João Paulo II (1990): "Perante a difusa degradação do ambiente, a humanidade já se vai dando conta de que não se pode continuar a usar os bens da terra como no passado. A opinião pública e os responsáveis políticos estão preocupados com isso; e os estudiosos das mais diversas disciplinas debruçam-se sobre as causas 
renunciou à tentação de fazer do mundo um "mero objeto de uso e domínio". Ao contrário, reconhecendo o Criador nas suas criaturas, deixava brotar dos seus lábios um cântico de louvor e percebia a natureza como um "livro esplêndido de Deus". 35

Reconhecendo Deus como o "autor da beleza", no Cântico das Criaturas, o poverello de Assis bendiz o Criador pela criação, reconhecendo-o como sua fonte e reconhecendo-a como dom. Quando, pois, se reconhece o mundo como dom e Deus como doador de tais bens, a atitude do homem religioso não pode ser outra, senão, o louvor, a ação de graças. E quem bendiz, não destrói; quem reconhece o dom, sabe conservá-lo.

Logo, o reconhecimento de Deus por meio da obra da criação leva, naturalmente, ao cuidado com a casa comum. A reflexão teológica não pode, pois, renunciar à tarefa de olhar a criação como "lugar teológico", uma vez que ela é, segundo se pode depreender de Sb 13,5, "sacramento" da "grandeza e beleza" do Criador.

\section{Conclusão}

O estudo do texto revelou que $\mathrm{Sb}$ 13,1-9 constitui uma unidade textual, tanto do ponto de vista da temática, quando da terminologia, onde, de modo

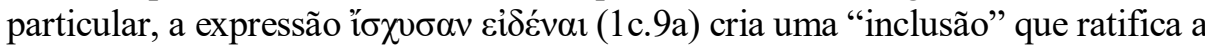
delimitação da perícope. Precedido por uma introdução (vv.1-2), o corpo do texto (vv.3-7) divide-se em três partes - vv.3-4; v.5; vv.6-7 - tendo como centro o v.5, com o princípio da analogia e a imagem do "Deus Genesiurgo". Os vv.8-9 servem de conclusão, onde se esclarece que, embora merecedores de uma punição mais branda (v.6), os que não transcendem as coisas criadas e terminam por idolatrá-las, ao invés de reconhecer o Senhor delas, não são desculpáveis (v.8).

Evocando em muitos lugares as tradições do Gênesis, o que se pôde perceber através da análise filológica e semântica de alguns termos, o texto tem como objetivo principal apresentar a Deus como Criador de todas as coisas, evocando a incoerência que existe nos que investigam "acuradamente"

do que sucede. Está assim a formar-se uma consciência ecológica, que não deve ser reprimida, mas antes favorecida, de maneira que se desenvolva e vá amadurecendo até encontrar expressão adequada em programas e iniciativas concretas". E, por fim, o pensamento do Papa Emérito Bento XVI: "O tema do desenvolvimento aparece, hoje, estreitamente associado também com os deveres que nascem do relacionamento do homem com o ambiente natural. Este foi dado por Deus a todos, constituindo o seu uso uma responsabilidade que temos para com os pobres, as gerações futuras e a humanidade inteira". (CV 48).

${ }^{35}$ LS 12. 
(v.7a.9b) as coisas terrestres, e não conseguem com a mesma facilidade (v.9c) chegar ao Criador. O autor sagrado, no v.5, evoca um princípio de validade geral, que não serve somente para reforçar a condenação dos idólatras ali apresentada, mas ajudará a inaugurar um método, o da analogia, que vai se desenvolver na Teologia, como uma via média entre o apofatismo e a univocidade, para que se possa perceber que é possível se elevar ao conhecimento do Deus invisível, por meio das coisas visíveis.

Por fim, a citação de Sb 13,5 no n. 12 da Laudato Si', parece ter como finalidade mostrar que a atitude encontrada em São Francisco é a que se espera de todo cristão que, inspirado pelo mesmo texto sagrado que possivelmente o inspirou, sente-se responsável por cuidar da casa comum, obra de Deus, reflexo de sua bondade, sacramento do seu amor por nós.

Duas citações podem deixar mais explícito que a consciência ecológica é, para um cristão, independente da época na qual ele vive, uma exigência inerente à fé. A primeira é de Santo Agostinho, quando comenta o S1 114, convidando ao louvor de Deus por meio da contemplação da beleza de suas obras: "incapazes diante de sua grandeza, olhemos para as suas obras, e tomando como ponto de partida as obras louvemos o artífice, do artefato o fabricante, da criatura, o Criador". ${ }^{36} \mathrm{Se}$, da contemplação da criação deve, segundo Agostinho e a tradição bíblica (Sb 13,5), nascer o louvor a Deus, como a Teologia poderia renunciar à sua tarefa de refletir a respeito das questões ecológicas? Trata-se, sem dúvida, de um tema que diz respeito a todos os homens mas, de modo particular, ao cristão, que, ao ler a Escritura e tomar conhecimento do testemunho da Tradição, percebe que a criação é um "Sacramento do Criador", um sinal vivo do seu amor por nós. O segundo texto é mais recente, trata-se de um pronunciamento de 1997 do Patriarca Ecumênico Bartolomeu I, conhecido como o Patriarca Verde. Suas palavras são tão firmes e eloquentes que dispensam comentários e servem de remate para tudo o que já foi refletido até então:

Cometer um crime contra o mundo natural é um pecado para os seres humanos. Assim também, causar a extinção das espécies e destruir a diversidade biológica da criação de Deus; degradar a integridade da terra, causando mudanças em seu clima, desnudando a terra de suas florestas naturais ou destruindo suas terras úmidas; ferir outros seres humanos

${ }^{36}$ AGOSTINHO, Comentário aos Salmos, 144,6. 
com doenças, contaminando as águas da terra, sua terra, seu ar e sua vida, com substâncias venenosas - tudo isso é pecado. ${ }^{37}$

\section{Referências bibliográficas}

AGOSTINHO. Comentário aos Salmos. São Paulo: Paulus, 1998. (Coleção Patrística, v. 9/3).

ALBERTZ, R. הֶרל. In: JENNI, E.; WESTERMANN, C. (Eds.). Diccionario Teológico Manual del Antiguo Testamento. Madrid: Ediciones Cristiandad, 1978. cc. 659-662. v.1.

ALONSO SCHÖKEL, L. דֶֶֶ. In: ALONSO SCHÖKEL, L. Dicionário Bíblico Hebraico-Português. São Paulo: Paulus, 1997. p. 166.

BAILLY, A. $\beta \varepsilon \lambda \tau i ́ \omega v$. In: BAILLY, A. Dictionnaire Grec-Français. Paris: Hachette, 2000. p. 356.

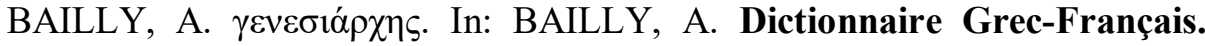
Paris: Hachette, 2000. p. 395.

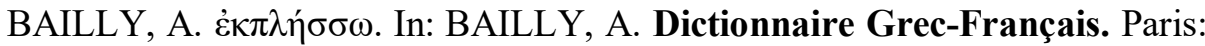
Hachette, 2000. p. 627.

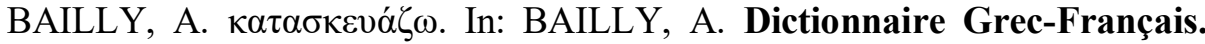
Paris: Hachette, 2000. p. 1052.

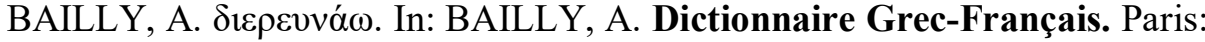
Hachette, 2000. p. 506.

BAILLY, A. $\sigma v \gamma \gamma v \omega \sigma \tau o ́ \varsigma$. In: BAILLY, A. Dictionnaire Grec-Français. Paris: Hachette, 2000. p. 1807.

BAILLY, A. $\sigma \tau о \chi \alpha ́ \zeta o \mu \alpha ı$. In: BAILLY, A. Dictionnaire Grec-Français. Paris: Hachette, 2000. p. 1797.

BENTO XVI, PP. Carta Encíclica Caritas in Veritate. São Paulo: Paulinas. 2009. BRAUN, H. $\pi \lambda \alpha v \alpha ́ \omega$. In: KITTEL, G.; FRIEDRICH, G. Theological Dictionary of the New Testament. Grand Rapids, MI: Eerdmans Publishing Co., 1968. p. 228-253. v. 6.

\footnotetext{
${ }^{37}$ Texto parcialmente citado pelo Papa Francisco, em setembro de 2016, no Dia Internacional de Oração pelo cuidado com a Criação.
} 
ELLIGER, K.; RUDOLPH, W. (Eds.). Biblia Hebraica Stuttgartensia. 5.ed. Stuttgart: Deutsche Bibelgesellschaft, 1997.

FRANCISCO, PP. Carta Encíclia Laudato Si’. São Paulo: Paulinas, 2015.

FRANCISCO, PP. Mensagem para o Dia Internacional de Oração pelo cuidado com a Criação. $<$ http://w2.vatican.va/content/francesco/pt/messages/pontmessages/2016/documents/papa-francesco_20160901_messaggio-giornatacura-creato.html>. Acesso em: 13 set. 2019.

GILBERT, M. La critique des Dieux dans le livre de la Sagesse: (Sg. 13-15). Roma: Biblical Institute Press, 1973.

JOÃO PAULO II, PP. Mensagem para o XXIII Dia Mundial da Paz. Disponível em: $\quad<$ https://w2.vatican.va/content/john-paul-ii/pt/messages/peace/documents/hf jpii_mes_19891208_xxiii-world-day-for-peace.html>. Acesso em: 20 set. 2019.

KOEHLER, L.; BAUMGARTNER, W. İשֶ. In: KOEHLER, L.; BAUMGARTNER, W. שֶׁ. The Hebrew and Aramaic Lexicon of the Old Testament. Leiden: Brill, 2001. p. 1425. v. 2.

LAFONT, G. Analogia. In: LATOURELLE, R.; FISICHELLA, R. Dicionário de Teologia Fundamental. Petrópolis: Vozes, 1994. p. 53-54.

LINDEZ, J. V. Sabedoria. São Paulo: Paulus, 1995.

LISOWSKY, G. Konkordanz zum Hebräischen Altes Testament. Stuttgart: Deutsche Bibelgesellschaft, 1993.

NICCACCI, A. Il Libro della Sapienza. Padova: Edizioni Messaggero, 2007.

PAULO VI, PP. Carta Apostólica Octogesima Adveniens. Disponível em: $<$ http://w2.vatican.va/content/paul-vi/pt/apost_letters/documents/hf_pvi_apl_19710514_octogesima-adveniens.html >. Acesso em: 27 set. 2019.

RAHLFS, A.; HANHART, R. (Eds.). Septuaginta. Stuttgart: Deutsche Bibelgesellschaft. 2006.

SAWYER, J. F. A. שְׁׁׁ. In: JENNI, E.; WESTERMANN, C. (Eds.). Diccionario Teologico Manual del Antiguo Testamento. Madrid: Ediciones Cristiandad, 1978. cc. 1107-1110. v.2.

SIEGFRIED, W. ברִּּש: In: RINGGREN, H.; FABRY, H.-J.; BOTTERWECK, G. J. (Eds.). Theological Dictionary of the Old Testament. Grand Rapids, MI: Eerdmans Publishing Co., 1975. p. 229-241. v.2. 
Fábio da Silveira Siqueira Doutor em Teologia pela Pontifícia Universidade Católica do Rio de Janeiro Rio de Janeiro / RJ - Brasil E-mail: padresiqueira@gmail.com

Recebido em: 28/09/19 Aprovado em: 09/12/19 